\title{
Clamping improves your judgment
}

\author{
Toyofumi F. Chen-Yoshikawa, MD
}

\author{
From the Department of Thoracic Surgery, Kyoto University Graduate School of Medicine, Kyoto, Japan. \\ Disclosures: Author has nothing to disclose with regard to commercial support. \\ Received for publication July 10, 2017; accepted for publication July 25, 2017; available ahead of print September \\ 6, 2017. \\ Address for reprints: Toyofumi F. Chen-Yoshikawa, MD, Department of Thoracic Surgery, Kyoto University \\ Graduate School of Medicine, 54 Shogoin Kawahara-cho, Sakyo-ku, Kyoto 606-8507, Japan (E-mail: \\ tfchenyoshikawa@gmail.com). \\ J Thorac Cardiovasc Surg 2017; 154:e93 \\ $0022-5223 / \$ 36.00$ \\ Copyright (C) 2017 by The American Association for Thoracic Surgery \\ http://dx.doi.org/10.1016/j.jtcvs.2017.07.041
}

The first clinical use of ex vivo lung perfusion (EVLP) in lung transplantation was reported by Steen and associates in $2001,{ }^{1}$ and a Toronto group reported the first clinical trial of EVLP in 2011. ${ }^{2}$ Since then, EVLP has become widely used in lung transplantation, and it is now established as a useful method for evaluation of the entire donor lung. Many clinicians have observed that injury of the donor lung is not always homogeneous; one lobe may be more damaged than the others. In such a case, the surgeon must rely on experience for a final decision, for example, when performing bilateral lung transplantation with resection of a damaged lobe. Several studies have considered issues such as regional evaluation during $\mathrm{EVLP}^{3}$; to date, however, no clinical report has described a clear and persuasive method.

In this issue of the Journal, Schweiger and colleagues ${ }^{4}$ report a case with selective lobar exclusion by venous clamping during EVLP. They used a simple method to evaluate the injured region of the donor lung and successfully performed a trilobar transplant. In the reported case, the donor lungs initially appeared marginal in terms of oxygenation, but Schweiger and colleagues ${ }^{4}$ found during EVLP that only the left lower lobe was damaged. The target region was so obvious that Schweiger and colleagues ${ }^{4}$ used this procedure for confirmation. Venous clamping can cause potentially irreversible damage to the lower lobe, however, so, as noted by Schweiger and colleagues, ${ }^{4}$ both arterial and venous clamping for selective lobar exclusion would be the best way to proceed if possible. Nonetheless, Schweiger and colleagues $^{4}$ are to be congratulated for clearly showing objective data on graft function of the remaining lobes.

Another notable feature of this article is the successful performance of a lobar lung transplant. When a lobar lung transplant is performed, the presence of a bronchial stump in either the donor or the recipient is a key issue. The data are missing in the report of Schweiger and colleagues, ${ }^{3}$

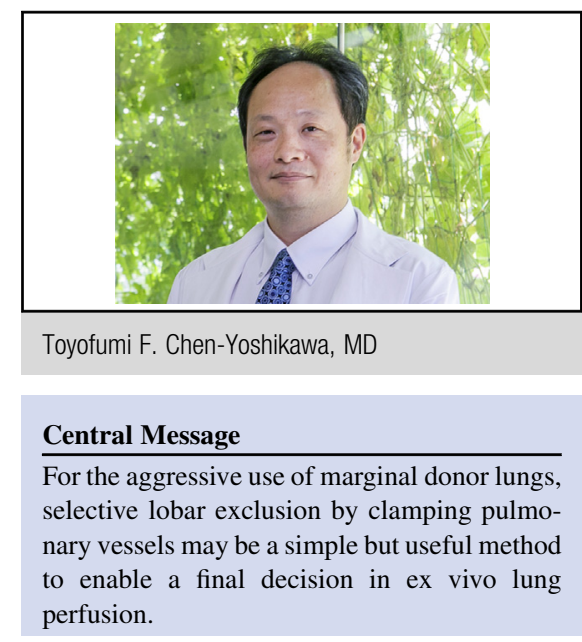

See Article page e87.

but long-term follow-up should be performed carefully, because the donor lungs were marginal in their case. To save more patients, however, given the severe worldwide donor shortage, surgeons should transplant potentially usable donor lungs, even when injured lobes require resection. Although living-donor lobar lung transplantation has not been widely performed, my own group's experience may be instructive.

In summary, the concept of pulmonary vessel clamping for evaluation of damaged donor lungs is novel. Both arterial and venous clamping, however, may be optimal for proper evaluation.

\section{References}

1. Steen S, Sjöberg T, Pierre L, Liao Q, Eriksson L, Algotsson L. Transplantation of lungs from a non-heart-beating donor. Lancet. 2001;357:825-9.

2. Cypel M, Yeung JC, Liu M, Anraku M, Chen F, Karolak W, et al. Normothermic ex vivo lung perfusion in clinical lung transplantation. N Engl J Med. 2011;364: $1431-40$.

3. Motoyama H, Chen F, Hijiya K, Kondo T, Ohata K, Takahshi M, et al. Novel thermographic detection of regional malperfusion caused by a thrombosis during ex vivo lung perfusion. Interact Cardiovasc Thorac Surg. 2015;20:242-7.

4. Schweiger T, Benazzo A, Lang G, Matilla JR, Klepetko W. Selective lobar exclusion by venous clamping during ex vivo lung perfusion. J Thorac Cardiovasc Surg. 2017; 154:e87-9.

5. Date H, Aoyama A, Hijiya K, Motoyama H, Handa T, Kinoshita H, et al Outcomes of various transplant procedures (single, sparing, inverted) in living-donor lobar lung transplantation. J Thorac Cardiovasc Surg. 2017;153: 479-86. 